\title{
Developing a Capability-Based Questionnaire for Assessing Well-Being in Patients with Chronic Pain
}

\section{Philip Kinghorn, Angela Robinson \& Richard D. Smith}

\section{Social Indicators Research}

An International and Interdisciplinary Journal for Quality-of-Life Measurement

ISSN 0303-8300

Volume 120

Number 3

Soc Indic Res (2015) 120:897-916

DOI 10.1007/s11205-014-0625-7

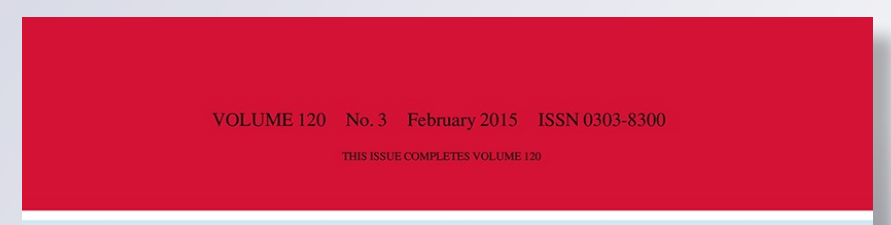

SOC I A L INDICA T ORS R E S E A R C H

AN INTERNATIONAL AND

IN TERDISCIPLINARY JOURNAL

FOR QUALITY-OF-LIFE MEASUREMENT

Editor: Filomena Maggino

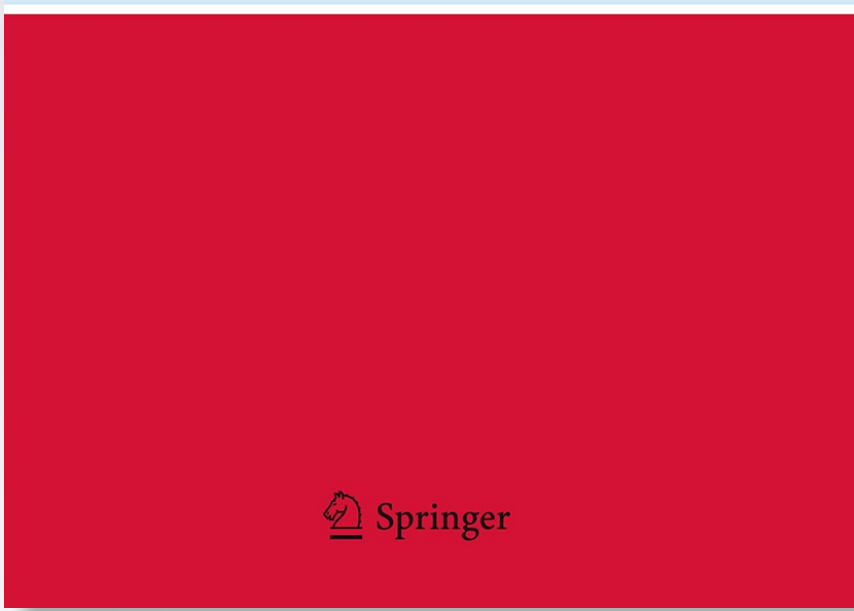


Your article is protected by copyright and all rights are held exclusively by Springer Science +Business Media Dordrecht. This e-offprint is for personal use only and shall not be selfarchived in electronic repositories. If you wish to self-archive your article, please use the accepted manuscript version for posting on your own website. You may further deposit the accepted manuscript version in any repository, provided it is only made publicly available 12 months after official publication or later and provided acknowledgement is given to the original source of publication and a link is inserted to the published article on Springer's website. The link must be accompanied by the following text: "The final publication is available at link.springer.com". 


\title{
Developing a Capability-Based Questionnaire for Assessing Well-Being in Patients with Chronic Pain
}

\author{
Philip Kinghorn • Angela Robinson • Richard D. Smith
}

Accepted: 10 April 2014/Published online: 20 April 2014

(C) Springer Science+Business Media Dordrecht 2014

\begin{abstract}
This paper reports a qualitative study which sought to operationalise Sen's capability approach in the context of chronic pain. The resulting capability-instrument will allow treatments and services to be evaluated according to whether they enable users to achieve those things which they value in life. This is particularly important in chronic conditions, where the emphasis is often on helping the patient to live their life as fully as possible despite persistent symptoms. Participatory methods were used to identify a list of capabilities deemed important to those with chronic pain. Respondents were recruited through a Pain Management Clinic in the East of England $(n=16)$. Focus groups were followed-up by individual interviews $(n=6)$. The following eight capabilities were identified as being important: Love and social inclusion; Enjoyment; Respect and Identity; Remaining physically and mentally active; Independence and autonomy; Societal and family roles; Physical and mental well-being; Feeling secure about the future. These have been developed into a questionnaire for self-completion by service users. The impact of chronic pain on well-being extends well beyond health symptoms and the range of health functionings typically considered when evaluating services. The capability-instrument is intended to supplement current evidence by assessing what service users are enabled to do. In its current form it will also be a useful tool for those seeking to deliver patient-centred care. Additional research into valuation and a decision-rule will progress capability as a stand-alone alternative economic framework.
\end{abstract}

\footnotetext{
P. Kinghorn $(\bowtie)$

Health Economics Unit, School of Health and Population Sciences, University of Birmingham,

Birmingham B15 2TT, UK

e-mail: p.kinghorn@bham.ac.uk
}

A. Robinson

Health Economics Group, Norwich Medical School, University of East Anglia, Norwich, UK

R. D. Smith

Faculty of Public Health and Policy, London School of Hygiene and Tropical Medicine, London, UK 
Keywords Capability · Chronic pain · Economic evaluation · Quality of life $\cdot$ UK

\section{Introduction}

Chronic pain is a condition that is prevalent across Europe (Breivik et al. 2006) and costly to the taxpayer (NHS Quality Improvement Scotland 2008). The effects of chronic pain, identified through a review of the nursing, psychology and neurophysiology literature (Breen 2002), included: alterations in sleep patterns; alterations in mobility (impacting upon activities of daily living); disability (resulting in loss of work); strained and dysfunctional relationships; psychological effects (such as depression); and alterations in social patterns.

Whilst curing the underlying causes of chronic pain would be the most effective way of enhancing well-being, a cure is rarely available; instead healthcare is most frequently targeted at helping patients to cope with pain (Coniam and Diamond 1994). Enhancing well-being for those with chronic pain may require a complex and diverse mix of interventions from across the health and social care systems (Department of Health 2010), including pain relief, psychotherapies, adapted housing and transport, income support and legislation such as the Equality Act (introduced in the UK in 2010). In general terms, the "interdedependence between the NHS and the adult social care system" is acknowledged (again) in the 2010 UK Government White Paper (2010). However, the framework typically used to evaluate and compare cost-effectiveness of health services [quality adjusted life years (QALYs)] fails to incorporate aspects of life important to patients and may not be sensitive to the types of outcomes delivered by social care.

QALYs are calculated by multiplying length of life by a weight reflecting health-related quality of life (HRQL). Changes in HRQL are typically reported directly by patients using generic instruments such as the EQ-5D, which includes: mobility; self-care; usual activities; anxiety and depression; pain and discomfort (The EUROQOL Group). The use of QALYs (including the use of EQ-5D) is currently required for technology appraisals submitted to the National Institute for Health and Care Excellence in England and Wales (NICE 2013). Similar recommendations are made by the equivalent organisations in Scotland, Canada and Australia (The Australian Medical Services Advisory Committee; The Australian Pharmaceutical Benefits Advisory Committee; The Canadian Agency for Drugs and Technologies in Health; The Scottish Medicine Consortium).

One alternative to the QALY, the capability approach (Nussbaum and Sen 1993; Sen 2010), is attracting increasing attention within health economics (Coast et al. 2008a, b, c). One strength of this approach, which focuses on the freedom and ability of individuals to lead a life that they have reason to value, is its wide informational base. This can incorporate more of what is important to patients and allow for the evaluation of a broader range of interventions.

The capability approach focuses on an important distinction between functionings and capabilities. Functionings are the various things that a person manages to do or be in leading a life (Nussbaum and Sen 1993, p. 31). The capability of a person is the alternative combinations of functionings the person can achieve, and from which he or she can choose one combination (Ibid.). The capability approach is a broad framework which can potentially be applied to a wide range of different policy issues and contexts (Sen 2010). 
A particular strength of the capability approach is the acknowledgement of human heterogeneity, which could be accommodated within a framework which focuses on freedom, but which would be much harder to accommodate using standardised units of outcome (Entwistle et al. 2012). In other words, a framework which focuses on our ability to do those things which we value (for example care for oneself with a reasonable degree of independence) will be more respectful of individual differences and priorities than one in which the equivalent outcome under focus is whether or not we can walk for ten yards unaided. The latter would fail to capture the freedom bestowed on a person who is, for example, able to get to local shops using a power-assisted wheelchair.

Broadly, there are three steps in operationalising the approach. First, identifying relevant capabilities. Second, assessing the impact of a programme or intervention in terms of the enhancement of capability (through use of questionnaires, national statistics or qualitative feedback from participants). The third step involves assessment of the relative importance of the different capabilities. This paper reports work relating to steps one and two in the context of chronic pain.

Section 2 of this paper introduces the various methodologies adopted by researchers using the capability approach. Section 3 describes the participatory approach adopted in this study and Sect. 4 presents the eight capabilities identified from patients with chronic pain. Section 5 contains a discussion of the findings and their potential use.

\section{Participatory Versus Expert Approaches}

Two approaches to identifying those capabilities which are relevant and valuable in the context of the research or policy question have emerged: the participatory approach and the expert approach. At a conceptual level, Robeyns (2005) and Alkire (2008) have both advocated the use of participatory methods, where those affected by a policy or intervention are involved in identifying valuable capabilities. At a more applied level, in-depth qualitative work was used to develop questionnaires to assess well-being in older people (The ICECAP-O) ${ }^{1}$ (Grewal et al. 2006) and in the general adult (UK) population (the ICECAP-A) (Al-Janabi et al. 2012). In both cases semi-structured interviews were used, together with constant comparative analysis.

An example of an expert approach is Nussbaum's (2011) list of ten central capabilities, developed purely through theoretical reasoning. Nussbaum presents the list as an invitation for debate within a peer group of academics and policy-makers. At the applied level, Nussbaum's list has been used as the basis for a questionnaire (Anand et al. 2005), which was then refined-using participatory methods-into an 18 item capability index, the OCAP-18, for use in evaluating complex public health interventions (Lorgelly et al. 2008).

Adoption of an expert approach can be justified in cases where ambitions, preferences and, in general, those things which participants would report as being valuable in life, are driven by adaptation. Nussbaum's list of central capabilities, for example, is intended as a set of rights, or requirements for a life to be "worthy of human dignity" (Nussbaum 2011, p. 32), against which the practices of governments and institutions can be assessed and challenged. Nussbaum therefore proposes a normative stance on what should constitute well-being across cultures. Alternatively, a list of capabilities (and corresponding functionings) may be selected by experts to match the availability of existing data.

${ }^{1}$ ICEpop CAPability measure for older people. 
However, limitations in using the expert approach to questionnaire development can be identified from previous studies. In developing the Oxford CAPabilities questionnaireMental Health (OxCAP-MH) as a multidimensional instrument aimed at operationalising the capability approach for outcome measurement within mental health research, Simon et al. (2013) adapted items from the OCAP-18 (see above). Initially the OXCAP-MH included 'property ownership', because of its relation to 'control over one's environment' from Nussbaum's work. Its inclusion in the OXCAP-MH was approved by an expert panel, but after conducting pilot work with service users, property ownership was later "deemed irrelevant and non-informative in the mental health context" (Simon et al. 2013, p. 13). A link between property ownership and well-being appears to rest on a strong value judgment and the expert-based approach can be open to charges of paternalism.

A participatory approach could be justified on the grounds that policies and interventions should be evaluated against outcomes which tax payers (as funders of public services) or patients (as recipients) regard as valuable. If care is to be patient-centred then we need some means of identifying those things which are intrinsically important to patients themselves. The starting point for a participatory approach is to identify what is important to the patient. In contrast, the expert approach starts with a list of attributes which are then piloted for relevance and acceptability to respondents. Piloting is hence the first exposure that attributes developed by experts will have had to broader scrutiny and it may be necessary at this stage to delete attributes which are found to be either irrelevant or not acceptable to respondents.

Here results are presented from participatory methods involving patients with chronic pain. Qualitative data from focus groups were analysed using framework, a "grounded" approach to classifying and organising data according to key themes, concepts and emergent categories (Pope et al. 2000; Ritchie and Lewis 2003). Framework is explicitly orientated towards applied policy questions and preserves the integrity of individual respondents' accounts throughout the analysis (Green and Thorogood 2009; Dixon-Woods 2011). Between the stages of distilling views and experiences from the focus groups and interpreting and defining concepts, a small number of individual interviews were conducted with original participants from the focus groups. This was an opportunity to test the validity of the themes initially identified and to use these themes as prompts to gather more in-depth data from participants. Final themes were developed into a questionnaire and, once again, at this stage there was service user involvement.

\section{Methodology}

\subsection{Sampling and Recruitment}

Participants were recruited through the Pain Management Clinic at an NHS hospital in the East of England during autumn 2006. Patients eligible to participate were those who had attended at least one previous appointment at the clinic and were aged over 18 years. Patients meeting the inclusion criteria were sent an invitation letter and information sheet prior to attending a routine appointment. When attending their appointment patients indicated whether or not they wished to take part in the study, and if so, signed a consent form. Ethics approval was granted by the local Research Ethics Committee (06/Q0101/ 130).

Once recruitment was complete, willing participants were contacted by telephone and arrangements for the focus groups finalised. 
As the objective was not to link specific experiences or symptoms to specific underling medical conditions information from medical notes regarding diagnosis was not recorded. All patients, however, were experiencing pain which was sufficiently severe to justify referral to a specialist clinic.

\subsection{Focus Groups}

The groups were asked to list any abilities, freedoms, activities or roles which they felt were valuable and which contributed to good quality of life. They were asked if their pain restricted their ability to do anything from this list. As participants responded they were prompted to provide further detail on how and why each of the outcomes they were seeking to achieve was of value to them and how being restricted in their ability to achieve the outcomes impacted on their quality of life. This process of moving from the initial response to uncovering the underlying personal value drew on the technique of laddering, a specific form of interviewing that takes a structured approach to data gathering (Miles and Rowe 2004; Sorensen and Askegaard 2007).

Each group was scheduled to last for up to one and a half hours. For five of the six groups the moderator (PK) was accompanied by a second researcher (one of the other authors) who interjected with questions where appropriate. An audio recording was made of the discussion, which was used (together with field notes) as the basis for analysis.

\subsection{Analysis}

Five stages of analysis were followed (Pope et al. 2000): (1) familiarisation; (2) identifying the thematic framework (identifying issues and themes); (3) indexing (applying the thematic framework systematically to all of the data); (4) Charting (here referred to as categorisation); (5) interpretation (defining concepts).

The analysis began with the researcher (PK) familiarising himself with the tape recordings by listening to entire recordings a number of times (Ritchie and Lewis 2003). From the initial three of the six tapes, themes were identified (key words or phrases, in the language of the participant). Then, for all six tapes, the location of these themes was recorded using the tape counter. An 'index' was then developed whereby themes were grouped under broader 'main themes'. Sections of discussion relating to main themes were then transcribed to form abridged transcripts (Krueger and Casey 2000) of those sections of discussion relating to determinants of a good life.

Categorisation involved bringing together main themes to form a smaller number of categories, and assigning 'labels' to these which could move away from the type of language used by participants. Classification involved a separation of these categories into two classes: (1) participants' feelings, for example anger or confusion, relating to the cause of their pain; (2) feelings and reported experiences relating to the impact of pain on wellbeing. Here we focus only on the impact of the pain.

From the initial analysis, ten main themes were identified and these are presented in the left-hand column of Table 1. These were then presented back to interview participants, after which analysis continued in order to refine the definitions of the main themes, which were interpreted as valuable capabilities. 


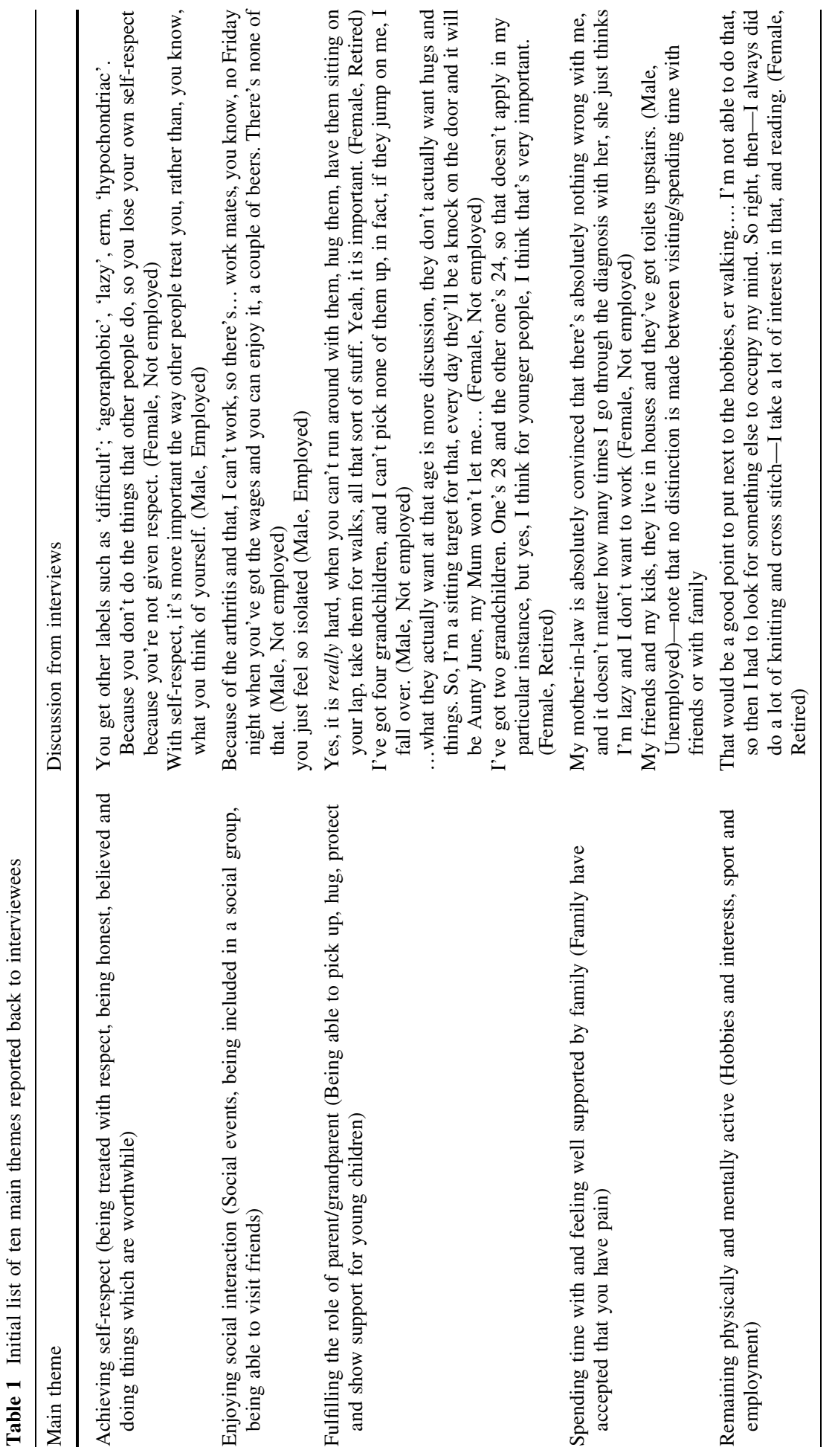




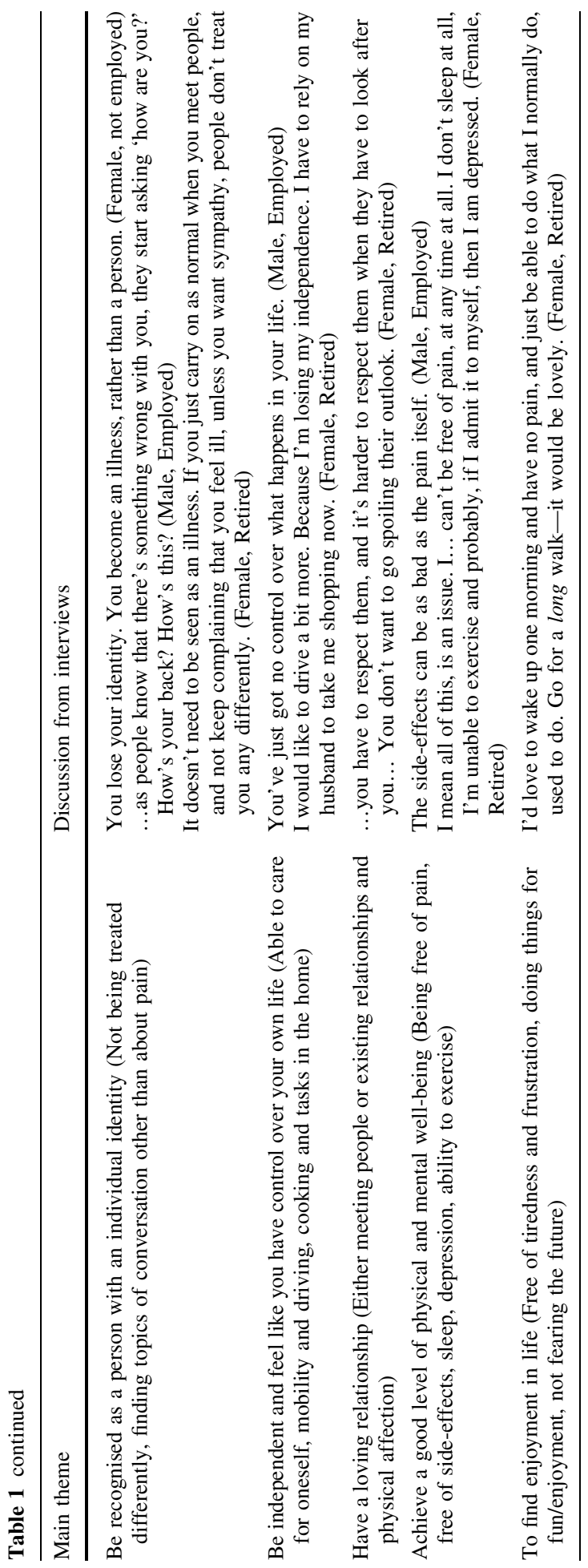




\subsection{Interviews}

Participants were offered the choice of conducting the interview at their home or at the Hospital. The number of interviews was determined by the number of participants who we were able to contact and who were available.

Participants were given the list of main themes identified from the focus groups (this represented the main element of the topic guide). Under each main theme was listed a number of associated themes, each with a brief description. Interviews were audio recorded and notes were taken by the interviewer.

\section{Results}

83 Patients were invited to participate, a total of 33 (40\%) gave consent. Across the groups, 16 participants actually attended. Seven participants were male, nine female, seven retired, three employed, six were of working age, but not employed. The youngest participant was 33 years of age and the oldest 81 years of age. One 'focus group' was conducted as an interview as only one participant attended. The actual duration of the focus groups ranged from 57 to $97 \mathrm{~min}$ (and $38 \mathrm{~min}$ in the case of the interview).

Conditions mentioned by participants included: back pain, fibromyalgia, arthritis and widespread pain. Two participants (one male and one female) were wheelchair users; several were reliant on sticks or crutches.

Six interviews were conducted in January and February 2007.

Of the ten main themes contained in Table 1, 'spending time with and feeling wellsupported by family' was dropped from the final list as it appeared to contain concepts which were already covered under the main themes relating to 'social interaction' and 'self-respect'. Participants in the interviews did not make a clear distinction between social time with friends and time with family. The two main themes relating to 'self-respect' and 'identity' were combined as participants in the interviews felt that achieving self-respect depended on how they were treated and the 'labels' given to those with illness or disability (quotes are provided in Table 1).

It was observed by the research team that views about relationships with partners and children could be categorised into (1) being loved and supported and (2) offering support and influencing the lives of others. Furthermore, it appeared that this extended beyond the immediate family. Hence a new main theme relating to societal and family roles was created and the main theme relating to social interaction was expanded to include 'being loved'. Finally, feelings and concerns relating to the future were differentiated from those relating to the ability to enjoy life in the present.

The resulting eight main themes are explored below and are interpreted here as valuable capabilities.

\subsection{Love and Social Inclusion}

This theme is about being loved and feeling included-a shared experience with, or response to, the love and friendship provided by others. Participants reported finding it difficult to meet people, sustain existing friendships and take part in social activities. Many spoke of feeling isolated. 
Employment is one way of meeting people and maintaining friendships. Prolonged absences or total withdrawal from employment make work-related friendships hard to sustain as the common bond and source of conversation is lost.

Limited mobility and an inability to sit or stand comfortably, result in difficulties taking part in social activities.

...my social life has become virtually nil. Even going to a neighbour for a cup of tea, they all stand in the kitchen, whereas I can't (Female, not employed, C)

The inconvenience and awkwardness of this (and in some cases embarrassment) can lead to self-withdrawal, or to invitations diminishing or stopping altogether.

It got to a stage where I just didn't want to go out anymore (Female, retired, C)

People phone you up and invite you out, but after a while they stop inviting you out 'cause they know you're going to come up with some excuse... (Male, not employed, C)

Of those participants who were single, some spoke of how their pain made it unlikely that they would meet a partner and build a relationship.

I'm on my own, sometimes very lonely, being in pain it feels like you're on your own all the time, and not being able to build a relationship with somebody because, the chronic pain is always there, it makes you grumpy, it makes you depressed. (Male, not employed, C)

Others spoke of how their pain interfered with the physical and emotional relationship they had with their partner.

He certainly doesn't see me as being sexy anymore... he sees himself as a carer. (Female, not employed, D)

It doesn't help your marriage either does it?...if he comes near me to cuddle me I'm on edge. (Female, retired, A)

I had a very full and satisfying sex life, but even that's dwindled down now. (Male, employed, A)

\subsection{Enjoyment}

Participants spoke of how there were activities that they used to do for fun, but which they could no longer do:

I can't dance anymore. And I did love dancing... I went to a wedding in September and...I couldn't get up and dance. I could have cried my eyes out. (Female, Retired, A)

You lose interest in, shopping. You know, it just, becomes a grudge. (Female, retired, C) You've lost the enjoyment? (Researcher)

That's right. There's no browsing anymore,

Because of the presence of pain, often together with tiredness, it seemed that there were days where respondents were 'in the wrong frame of mind' to experience enjoyment. Linked to this was the unpredictable nature of pain, and hence a trend of good and bad days.

...if I feel fine up top I'll have a better day. But if I wake up in the morning and I don't feel right up here, you know the day is going to be worse (Male, not employed, B) 
When my pain comes on I get short-tempered. (Male, employed, B)

\subsection{Respect and Identity}

Because the presence of pain is not easily visible, other people question whether it is genuine or whether those reporting pain are 'putting on an act' or 'seeking attention'. There were stories of how, when attempting to claim income support or other assistance, 'officials' were hostile and challenged the extent to which patients were debilitated by pain.

Because of the fear that people do not believe them or are bored by their pain participants battle to find a balance between being honest and 'selling the story' that they are suffering less than they actually are. Other people appear confused by the fact that they are experiencing no improvement.

I always hate when someone says 'how are you?' I can't lie to 'em, I can't turn round and say I'm absolutely bloody fine, when I'm not, you know. But you can't, you can't turn round and say ah, terrible! (Male, not employed, B)

When people ask if you're alright, at some point they want to hear a positive response don't they, and if they don't, they don't know how to deal with it. (Male, not employed, C)

Asking for help can be embarrassing and, similarly, participants worry that other people view them unfavourably when they are unable to offer assistance to others. Some participants reported feeling weak and hopeless.

You just feel as though you want to hide away in a corner sometimes; when you're with a lot of people, you feel ashamed. (Female, retired, C)

Participants spoke of how the constant pain and the resulting tiredness, frustration and, in some cases, depression had altered their personality. Those who had been forced to give up work or hobbies said that little happened in their lives that they wanted to discuss in conversation. There was a feeling of being defined as someone with an illness, and that the illness had become their identity.

If you think, like to think of yourself as an interesting person, you don't want to become an illness, so the first thing people say to me is 'how are you today?', not 'what have you been doing?' (Female, not employed, C)

I notice it more in the wheelchair. People don't talk to me, they talk to who's pushing me, so I'm just the person sitting there... obviously not capable of any thought or decision (Female, retired, C)

\subsection{Remaining Physically and Mentally Active}

This theme is about passing the time with activities which are productive and stimulating. Participants spoke of having to give up certain hobbies and interests, or experiencing greater difficulty in undertaking them. Particularly when respondents have had to give up work or are retired, hobbies are important in order to pass the time and prevent boredom.

The reason I knit and cross-stitch is to, I've got to do something. Otherwise you'd go crazy. (F retired, C) 
Work is important. Just to go out and do things that aren't mind numbing if you know what I mean. (F employed)

\subsection{Independence and Autonomy}

It is losing your independence isn't it, if someone's got to do everything for you. (Female, retired, B)

Pain limits the ability of participants to cook, look after the home, dress, shower and take a bath. Outside of the home, participants reported limitations with their ability to travel, shop and so on.

Now, I have to instruct someone when to take something out the freezer, and, it's very frustrating... (Female, not employed, B)

... say you want some milk from the shop, that's only just down the road, but I can't walk and get it... (Female, retired, B)

I'm not able to drive anymore. Whereas I used to drive (Female, retired, C)

Is it due to pain? (Researcher)

Well, I can't put any pressure on my feet, and I've got arthritis and that in this arm... ...is driving something that you regard as being important? (Researcher)

Oh yes. Well, its independence isn't it. I'm so reliant on [husband] that he has to be with me really all of the time

Some participants also spoke of having to base their routine around their pain or their medication.

This morning, I got up-5 o'clock-I took my first pain killers, went back to bed again so that I was ready to get up to have my shower at half past six, or else, by the time you start taking them they haven't taken effect and you're trying to move around. So, yeah, you've got to think ahead... (Female, not employed, A)

One participant spoke of how she had thrown away the medication which had been prescribed to her and turned instead to herbal remedies. The action could be interpreted as an attempt to take control of her treatment.

\subsection{Societal and Family Roles}

This theme is about the impact of the respondents on the lives of others, in terms of their role as husband/wife, parent/grandparent, sister/brother, and so on. There seemed to be a feeling by the participants that these roles played a key part in defining who they were. Many participants spoke of feeling guilty that someone in their life was somehow 'missing out' because of their pain. A lot of concern was expressed about the well-being of others.

Don't you feel as if you're letting your family down? Cos I feel like I've let my wife down this last holiday... (Male, employed, A)

I don't know if anyone else feels guilty, I have a huge guilt complex that I worry that I put all this stuff on to my husband (Female, not employed, C) 
One issue discussed by respondents was the ability to pick up, hug and protect young children, another was not being able to play with and take part in activities with children. One participant spoke of how just walking across the pitches to where his son was playing football resulted in extreme pain and how this prevented him from supporting his son in the way he wanted to. All of these things are detrimental to the relationship between child and parent/grandparent.

My husband seems to have a better relationship with her in that way, in that if she hurts herself she'll run to him for a hug, rather than me because I can't pick her up.... You feel a bit left out really. (Female, employed, A)

It was noted by two of the authors after a discussion amongst several male respondents that the perception of role appeared to be associated with an element of 'male pride'. An example from two groups is a husband not being able to help his wife to bring in shopping from the car. As well as wanting to be helpful (perhaps chivalrous), there was also concern about the perceptions of neighbours.

\subsection{Physical and Mental Well-Being}

I'm in pain 24-7, whether I'm laying down, in the bath or hanging from the lightshade, I'm in bloody pain (Male, not employed, B)

Pain affects sleep, the ability to exercise, is itself tiring, and medication often results in unpleasant side-effects.

I take morphine, but I try not to take it too often, and working through the pain, you're debilitated, you're sleepy after you've taken your pills. You're exhausted. You've not done anything,...but you're exhausted (Female, not employed, C)

Pain is very tiring (Female, not employed, B)

Yes, it is very tiring (Female, not employed, C)

The medication that I have tried has been horrible, has done horrible things to me (Female, not employed, B)

Many of the participants also reported some degree of depression.

I started getting depression... it's like yesterday, I didn't have a wash, I didn't have a shave, I didn't get up, I didn't even unlock the door, and that was it (Male, not employed, A)

\subsection{Feeling Secure About the Future}

Concerns for the future are another burden for some participants. Concerns mainly stem from the knowledge that their condition is likely to worsen, and relate to finances, relationships, and their ability to cope.

My main concern is if anything happened to my husband, he's...fit and healthy and everything, but he is everything, he's always been my world anyway, but now he is my physical world as well as my emotional world because he does everything. So, that is, something that is always in the back of my mind. (Female, not employed, C).

It's an extreme worry, having the children and not being able to work. I'm only $47 \ldots$ (Male, employed, B) 
In one focus group there was a sharp contrast between the concerns expressed by one participant (who had experienced back pain for many years) and the hope expressed by another (who had experienced pain for a few months following a work-related injury). However, the quote by the latter still reveals some acknowledgement of the uncertainty:

I'm looking good for the future (hopefully), but after the scan, ask me then and I might change my opinion. (Male, employed, A)

Where there were differences between individual responses these appeared to be mostly driven by differences in gender and pain severity. When it came to relationships and identity, female participants seemed to worry more about their pain making them feel older and making them less attractive to their partners. Male participants tended to place importance on the ability to do tasks that they felt defined the role of the man, such as carrying heavy items and cutting the grass.

...you feel inadequate. Well I do, when my missus starts...unloading the car, and I

walk into the house and sit down. (M employed, A)

Participants who had suffered with severe pain for a long time seemed to suffer more sideeffects from powerful medication, were often resigned to the fact that their pain would get worse and tended to speak of depression.

\section{Development and Proposed Use of a Capability-based Pain Questionnaire}

The capability approach offers a means of assessing benefits from health and social care services. This requires us to define levels for the capabilities and assess achievement (or ability) against these standardised levels. In groups susceptible to adaptation, a (more) objective means of assessing well-being may be to use observed functioning as a proxy for capability, but any link between ability and outcome will, as Sen states (1979, 2010), be complex and dependent upon the individual's characteristics and circumstances. In terms of assessment of capability, it is unlikely that expert assessment of social abilities and outcomes would be more valid than assessment by the individual themselves. It is important to acknowledge, as when deciding how to arrive at a set of attributes, that people view things differently depending upon where they are situated (their "standpoint"), socially and culturally; we cannot resolve the debate here as to whose viewpoint is correct, but we see no reason to assume that expert assessment will be any less susceptible to bias. The instrument presented in this paper is intended for self-completion, following the lead set by the developers of ICECAP-O and ICECAP-A (Coast et al. 2008; Al-Janabi et al. 2012).

From the qualitative work reported above a capability-based questionnaire was developed and refined through discussion with colleagues and through a service user group convened by the Aberdeen Pain Research Collaboration. Labels given to the capabilities in section 3 were re-phrased to refer to "my health", "the impact I have", etc. and where necessary lay terminology was adopted. Four levels are defined for each capability. The three-level version of the EQ-5D is known to have ceiling effects, and one motivation for developing the new five-level version has been to increase sensitivity (Herdman et al. 2011). ICECAP-A and ICECAP-O (the most closely comparable questionnaires to ours, in terms of theory and wording) are both four-level instruments and have been found to have good validity (Coast et al. 2008). It has been suggested in the market research literature that a distinction should be drawn between having the maximum number of levels which 
respondents can discriminate between (sensitivity) and the number of levels which are meaningful to them (Viswanathan et al. 2004). Four was the limit at which it was agreed a meaningful distinction could be made between levels, and four levels avoids the potential problem of having a middle level, often interpreted by respondents as being some kind of "average" against which they should compare themselves (Bradburn et al. 2004). The resulting questionnaire is contained in the "Appendix".

Much of the discussion within the service user group centred on the first attribute (Being loved and having friendship). The attribute is deliberately broad as it is acknowledged that across a sample there will be respondents in different circumstances and with different religious and cultural beliefs. Participants highlighted that love can be interpreted in many ways, with one participant stating that the only person she had loved was her father, and another differentiating between being loved and "being in love". We took from this that participants were able to interpret "love" in a way that was meaningful and relevant for them. Participants were quick to pick out the attribute relating to respect and confirmed the importance of this; one participant spoke of not wanting to be seen as special, while another referred to people being "disrespectful". One participant had written the following comments on their questionnaire: "Very good to understand"; "easy to fill out"; "covers all areas I could think of being important".

The different combinations of levels across the capabilities will define individual 'capability states', which can be valued as part of future work. The capability approach is not wedded to any particular decision-rule, although those advocating the use of capability are critical of maximisation (Coast 2009; Ruger 2010). We have no evidence at present as to which decision-rule would be most acceptable to society and suggest that this is an area in need of further research.

\section{Discussion}

This paper, for the first time, explored the capability approach within the context of chronic illness. Qualitative work was used to inform the development of a questionnaire, which could be used in evaluating both health and non-health interventions targeted at those with chronic pain. Eight capabilities were found to be of value to those with chronic pain.

Although there are a small number of existing capability-based questionnaires [including the ICECAP-A, for use in the general adult population (Al-Janabi et al. 2012), the ICECAP-O, for use with older people (Grewal et al. 2006) and the OCAP-18 for assessing public health outcomes (Lorgelly et al. 2008)], none of these instruments was developed for use in the context of chronic pain and there is no evidence as yet on the validity of the measures for this population group. Dimensions from these instruments are listed in Table 2. Although there is some commonality, it must be realised that the lists were developed using different methods and for use in different contexts.

Strengths of the work include the participant-led generation of important capabilities and that participants were engaged and forthcoming in this process; generally, the dynamic within groups was positive, supportive and open. Further, participants were not limited to a particular gender, age or underlying medical condition. There is an extensive literature on chronic pain, although many of the previous qualitative studies have tended to focus on specific conditions [such as low-back pain (Corbett et al. 2007)], specific demographic groups (Blomqvist and Edberg 2002; Richardson 2005; Richardson et al. 2006), or specific kinds of impact [e.g. on the family (Snelling 1994), social participation (Borell et al. 2006), sexual function (Kwan et al. 2005)]. For example, Werner et al. (2004) explore issues of 
Table 2 Comparison of attributes in the capability-based questionnaire for chronic pain with attributes in existing capability measures

\begin{tabular}{|c|c|c|c|}
\hline $\begin{array}{l}\text { Capability-based } \\
\text { questionnaire for chronic } \\
\text { pain }\end{array}$ & ICECAP-A & ICECAP-O & $\begin{array}{l}18 \text { Dimension measure } \\
\text { for use in Public Health }\end{array}$ \\
\hline $\begin{array}{l}\text { Love and social } \\
\text { inclusion }\end{array}$ & $\begin{array}{l}\text { Attachment (love, } \\
\text { friendship and } \\
\text { support) }\end{array}$ & $\begin{array}{l}\text { Attachment (love and } \\
\text { friendship) }\end{array}$ & $\begin{array}{l}\text { Love and support } \\
\text { Social networks }\end{array}$ \\
\hline Enjoyment & $\begin{array}{l}\text { Enjoyment } \\
\text { (enjoyment and } \\
\text { pleasure) }\end{array}$ & $\begin{array}{l}\text { Enjoyment (enjoyment and } \\
\text { pleasure) }\end{array}$ & $\begin{array}{l}\text { Enjoy recreation } \\
\text { Appreciate nature }\end{array}$ \\
\hline Respect and identity & $\begin{array}{l}\text { Achievement } \\
\text { (achievement and } \\
\text { progress) }\end{array}$ & - & $\begin{array}{l}\text { Respect and appreciation } \\
\text { Discrimination } \\
\text { Freedom of expression }\end{array}$ \\
\hline \multirow[t]{2}{*}{$\begin{array}{l}\text { Remaining physically } \\
\text { and mentally active }\end{array}$} & & & $\begin{array}{l}\text { Employment } \\
\text { discrimination }\end{array}$ \\
\hline & & $\begin{array}{l}\text { Role (doing things which } \\
\text { make you feel valued }\end{array}$ & $\begin{array}{l}\text { Imagination and } \\
\text { creativity } \\
\text { Daily activities }\end{array}$ \\
\hline Societal and family roles & - & & Influence local decisions \\
\hline $\begin{array}{l}\text { Independence and } \\
\text { autonomy }\end{array}$ & $\begin{array}{l}\text { Autonomy (being } \\
\text { independent) }\end{array}$ & Control (independence) & $\begin{array}{l}\text { Planning one's life } \\
\text { Suitable accommodation }\end{array}$ \\
\hline $\begin{array}{l}\text { Physical and mental } \\
\text { well-being }\end{array}$ & - & - & $\begin{array}{l}\text { Life expectancy } \\
\text { Losing sleep }\end{array}$ \\
\hline $\begin{array}{l}\text { Feeling secure about the } \\
\text { future }\end{array}$ & $\begin{array}{l}\text { Stability (feeling } \\
\text { settled and secure) }\end{array}$ & $\begin{array}{l}\text { Security (thinking about } \\
\text { the future without } \\
\text { concern) }\end{array}$ & $\begin{array}{l}\text { Property ownership } \\
\text { Neighbourhood safety } \\
\text { Potential for assault }\end{array}$ \\
\hline
\end{tabular}

Loose mapping between instruments for illustration only. This is unlikely to reflect the true complexity

The use of '-' indicates that there is no attribute on this questionnaire which obviously corresponds to the attribute on the other questionnaire(s)

self and shame in women with chronic pain. Themes identified from previous literature are reported in Table 3. A characteristic of reported studies is that work has been conducted with specific groups or on pre-defined themes, and therefore the results are limited in terms of generalizability across all groups with chronic pain.

Themes listed in Table 3 largely relate to the functional level (for example driving and lifting), whereas the capability-based questionnaire developed here aims to capture the ability to achieve valuable outcomes, such as maintaining independence. A link between the two (cause and effect) can be traced, and understanding of the links enhanced through the qualitative work reported above.

There were, however, limitations. It was impossible to arrange focus groups at times which were convenient for every potential participant. Even when patients indicated that they could attend at a particular time, some did not. This may have affected the type of respondents participating. Low participation may be explained by the fact that these patients tend to experience difficulties with transport, are unable to sit comfortably for long durations and (as previous research indicates) are reluctant to discuss their pain, even when invited to do so (Richardson 2005). Non-attendance may, in part, be explained by the unpredictable nature of pain. 
Table 3 Themes from the literature

\begin{tabular}{|c|c|}
\hline Theme & Description \\
\hline Pain itself & $\begin{array}{l}\text { Intensity, frequency and location [see quantitative rather than qualitative } \\
\text { studies, such as Thomas et al. (2004)] }\end{array}$ \\
\hline Medical treatment & $\begin{array}{l}\text { Those with severe pain make greater use of healthcare than those with } \\
\text { moderate pain, but are less satisfied with treatment (Loeser and Melzack } \\
\text { 1999; Dewar et al. 2003; Hadjimichael et al. 2007) }\end{array}$ \\
\hline $\begin{array}{l}\text { Meaning and } \\
\text { understanding }\end{array}$ & $\begin{array}{l}\text { Lack of understanding around the cause and meaning of pain and insufficient } \\
\text { knowledge to make treatment choices (Paulson et al. 2002) }\end{array}$ \\
\hline Legitimisation and identity & $\begin{array}{l}\text { Respondents go to extreme lengths to hide their pain, avoid talking about pain } \\
\text { and seek to maintain a positive identity (Werner et al. 2004; Richardson } \\
\text { 2005) }\end{array}$ \\
\hline Daily activities & $\begin{array}{l}\text { Pain is known to interfere with dressing, undressing, lifting, driving, doing } \\
\text { housework, recreational activities and employment (Carson and Mitchell } \\
\text { 1998; Breen 2002; Dewar et al. 2003) }\end{array}$ \\
\hline Sleep disturbance & In turn, has an impact on other areas of life (Breen 2002; Dewar et al. 2003) \\
\hline Relationships & $\begin{array}{l}\text { Pain causes role tension, marital conflict, reduced sexual activity, and feelings } \\
\text { of anger, anxiety, resentment and despondency in other family members } \\
\text { (Snelling 1994; Raheim and Haland 2006) }\end{array}$ \\
\hline $\begin{array}{l}\text { Social issues and } \\
\text { loneliness }\end{array}$ & $\begin{array}{l}\text { Difficulty interacting with friends, family and society, isolation through not } \\
\text { being able to work, and the impact of the unpredictable nature of pain on } \\
\text { social participation (Snelling 1994; Carson and Mitchell 1998; Dewar et al. } \\
\text { 2003) }\end{array}$ \\
\hline $\begin{array}{l}\text { Psychological and } \\
\text { emotional distress }\end{array}$ & $\begin{array}{l}\text { Mood swings and negative feelings, frustration, anxiety, grief, hopelessness } \\
\text { and depression (Breen 2002; Dewar et al. 2003; Kothe et al. 2007) }\end{array}$ \\
\hline
\end{tabular}

Whilst we are confident that saturation was reached in terms of identifying the main themes, it is acknowledged that a larger sample size would have strengthened the study and it is unclear whether additional 'codes' would have been identified had more focus groups been conducted. Additional codes may have influenced the definitions given to the final set of capabilities. However, the service user group brought additional views, and experiences and feedback from this group did not highlight a need for amendments to the questionnaire.

What is not possible with the sample size in this study is to fully describe and explore the routes through which chronic pain, and, in a secondary sense, factors such as people's reactions to chronic pain and physical environments, limit capability and this is suggested as an area for future research as understanding of this may drive improvements in the support which can be offered to patients.

While incorporating everything that is important to patients into an outcome measure may not be feasible (without generalising 'attributes' to a very abstract level), adopting a broader informational base for economic evaluation would be helpful for evaluating across sectors. This work identified a list of capabilities that will be important in evaluating crosssectoral interventions for those with chronic pain and presents a tool, in the form of the questionnaire, through which this can be done. Next steps will involve assessing the validity of the instrument, through its inclusion alongside and comparison with both established generic and condition-specific instruments. In its current form, it will offer service providers a systematic means of capturing outcomes which extend beyond health symptoms; it will give an indication of whether services enable users to be and do those things which are of value to them. Condition-specific instruments are not typically used in economic evaluation. Whilst eliciting values for this instrument will enhance its use in 
terms of gathering additional economic evidence to inform policy-makers, a generic capability-instrument which explicitly incorporates health could offer a stand-alone alternative to the QALY.

Acknowledgments Funding was received from the Pain Management Clinic at the James Paget University NHS Hospital and from a University of East Anglia studentship. As well as the patients and staff at the clinic, we would like to thank members of the Service User Group, convened by the Aberdeen Pain Research Collaboration.

\section{Appendix: A Capability-Based Questionnaire for Assessing Well-Being in Patients with Chronic Pain}

1. Being loved and having friendship.

- I am able to have a lot of love and contact with friends or family

- I am able to have quite a lot of love and contact with friends or family

- I am able to have little love and contact with friends or family

- I am not able to have any love or contact with friends or family

2. Being able to do things for fun (Including being in the 'right frame of mind' to experience enjoyment in life).

- I am able to get a lot of enjoyment in life

- I am able to get quite a lot of enjoyment in life

- I am able to get little enjoyment in life

- I am not able to get any enjoyment in life

3. Being open, honest, believed, respected and understood (Not being defined as a person with ill health).

- I am able to feel totally respected and positive about who I am

- I am able to feel largely respected and positive about who I am

- I am able to feel somewhat respected and positive about who I am

- I am not able to feel respected or positive about who I am

4. Doing things which are productive and interesting (for example, hobbies, work or sport).

- I am able to be totally active (both body and mind)

- I am able to be largely active (both body and mind)

- I am able to be somewhat active (both body and mind)

- I am not able to be active (both body and mind)

5. Being independent and being able to make decisions.

- I am able to be as independent as I want to be

- I am able to be almost as independent as I want to be

- I am able to be much less independent than I want to be

- I am not be able to be independent

6. The impact that I have on the lives of others (including: partners, family, colleagues and my local community).

- I am able to contribute to the well-being and happiness of those closest to me, in many ways 
- I am able to contribute to the well-being and happiness of those closest to me, in some ways

- I am able to contribute to the well-being and happiness of those closest to me, in few ways

- I am not at all able to contribute to the well-being and happiness of those closest to me

7. My health and mental well-being (including: pain, depression, sleep, mobility, medication side-effects).

- I have no problems with my physical health or mental well-being

- I have minor problems with my physical health or mental well-being

- I have moderate problems with my physical health or mental well-being

- I have severe problems with my physical health or mental well-being

8. Knowing that in the future I will be able to cope

- When I think about the future I am able to feel completely confident that I will cope

- When I think about the future I am able to feel largely confident that I will cope

- When I think about the future I am able to have little confidence that I will cope

- When I think about the future I am not able to have any confidence that I will cope

\section{References}

Al-Janabi, H., Flynn, T., et al. (2012). Development of a self-report measure of capability wellbeing for adults: the ICECAP-A. Quality of Life Research, 21(1), 167-176.

Alkire, S. (2008). Using the capability approach: Prospective and evaluative analyses. In F. Comin, M. Qizilbash, \& S. Alkire (Eds.), The capability approach: Concepts, measures and applications. New York: Cambridge University Press.

Anand, P., Hunter, G., et al. (2005). Capabilities and well-being: Evidence based on the sen-nussbaum approach to welfare. Social Indicators Research, 74(1), 9-55.

Blomqvist, K., \& Edberg, A. (2002). Living with persistent pain: Experiences of older people receiving home care. Journal of Advanced Nursing, 40(3), 297-306.

Borell, L., Asaba, E., et al. (2006). Exploring experiences of "participation" among individuals living with chronic pain. Scandinavian Journal of Occupational Therapy, 13, 76-85.

Bradburn, N., Sudman, S., et al. (2004). Asking questions: The definitive guide to questionnaire design for market research, political polls, and social and health questionnaires. San Francisco: Jossey-Bass.

Breen, J. (2002). Transitions in the concept of chronic pain. Advanced Nursing Science, 24(4), 48-59.

Breivik, H., Collett, B., et al. (2006). Survey of chronic pain in Europe: Prevalence, impact on daily life, and treatment. European Journal of Pain, 10, 287-333.

Carson, M. G., \& Mitchell, G. J. (1998). The experience of living with persistent pain. Journal of Advanced Nursing, 28(6), 1242-1248.

Coast, J. (2009). Maximisation in extra-welfarism: A critique of the current position in health economics. Social Science and Medicine, 69, 786-792.

Coast, J., Peters, T., et al. (2008a). An Assessment of the construct validity of the descriptive system for the ICECAP capability measure for older people. Qualitative Life Research, 17, 967-976.

Coast, J., Smith, R. D., et al. (2008b). The influence of capabilities on health care decision making in the UK. Social Science and Medicine, 67, 1190-1198.

Coast, J., Smith, R. D., et al. (2008c). Welfarism, extra-welfarism and capability: The spread of ideas in health economics. Social Science and Medicine, 67, 1190-1198.

Coast, J., Smith, R. D., et al. (2008d). Should the capability approach be applied in health economics? Health Economics, 17, 667-670. 
Coniam, S. W., \& Diamond, A. W. (1994). Practical pain management. Oxford: Oxford Medical Publications.

Corbett, M., Foster, N., et al. (2007). Living with low back pain-stories of hope and despair. Social Science and Medicine, 65, 1584-1594.

Department of Health. (2010). Equity and excellence: Liberating the NHS. White Paper.

Dewar, A., White, M., et al. (2003). Using nominal group technique to assess chronic pain, patients' perceived challenges and needs in a community health region. Health Expectations, 6, 44-52.

Dixon-Woods, M. (2011). Using framework-based synthesis for conducting reviews of qualitative studies. BMC Medicine, 9(39): Commentary 39.

Entwistle, V., Firnigl, D., et al. (2012). Which experiences of health care delivery matter to service users and why? A critical interpretive synthesis and conceptual map. Journal of Health Services Research and Policy, 17(2), 70-78.

Green, J., \& Thorogood, N. (2009). Qualitative methods for health research. London: SAGE.

Grewal, I., Lewis, J., et al. (2006). Developing attributes for a generic quality of life measure for older people: Preferences or capabilities? Social Science and Medicine, 62, 1891-1901.

Hadjimichael, O., Kerns, R. D., et al. (2007). Persistent pain and uncomfortable sensations in persons with multiple sclerosis. Pain, 127, 35-41.

Herdman, M., Gudex, C., et al. (2011). Development and preliminary testing of the new five-level version of EQ-5D (EQ-5D-5L). Quality of Life Research, 20, 1727-1736.

Kothe, R., Kohlmann, T. et al. (2007). Impact of low back pain on functional limitations, depressed mood and quality of life in patients with rheumatoid arthritis. Pain, 127(1-2), 103-108.

Krueger, R. A., \& Casey, M. A. (2000). Focus groups: A practical guide for applied research. California: Sage.

Kwan, K. S. H., Roberts, L. J., et al. (2005). Sexual dysfunction and chronic pain: The role of psychological variables and impact on quality of life. European Journal of Pain, 9(6), 643-652.

Loeser, J. D., \& Melzack, R. (1999). Pain: An overview. Lancet, 353(9164), 1607-1609.

Lorgelly, P., Lorimer, K., et al. (2008). The capability approach: Developing an instrument for evaluating public health interventions. Glasgow: University of Glasgow.

Miles, S., \& Rowe, G. (2004). The laddering technique. In G. M. Breakwell (Ed.), Doing social psychology research. Oxford: BPS Blackwell.

NHS Quality Improvement Scotland. (2008). Getting to GRIPS with chronic pain in Scotland: Getting relevant information on pain services (2nd ed.). http://www.nationalpainaudit.org/media/files/GRIPS_ booklet.pdf. Accessed 3 Oct 2011.

NICE. (2013). Guide to the methods of technology appraisal 2013. Process and Methods Guides 04 April. http://publications.nice.org.uk/pmg9.

Nussbaum, M. (2011). Creating capabilities: The human development approach. Harvard: Harvard University Press.

Nussbaum, M., \& Sen, A. (1993). The quality of life. Oxford: Clarendon Press.

Paulson, M., Danielson, E., et al. (2002). Struggling for a tolerable existence: The meaning of men's lived experiences of living with pain of fibromyalgia type. Qualitative Health Research, 12(2), 238-249.

Pope, C., Ziebland, S., et al. (2000). Qualitative research in health care: Analysing qualitative data. BMJ Education and Debate, 320, 114-116.

Raheim, M., \& Haland, W. (2006). Lived experience of chronic pain and fibromyalgia: Women's stories of daily life. Qualitative Health Research, 16(6), 741-761.

Richardson, J. (2005). Establishing the (extra)ordinary in chronic widespread pain. Health, 9(1), 31-48.

Richardson, J., Ong, B. E., et al. (2006). Is chronic widespread pain biographically disruptive. Social Science and Medicine, 63, 1573-1585.

Ritchie, J., \& Lewis, J. (2003). Qualitative research practice: A guide for social science students and researchers. London: Sage Publications.

Robeyns, I. (2005). Selecting capabilities for quality of life measurement. Social Indicators Research, 74, $191-215$.

Ruger, J. P. (2010). Health and social justice. New York: Oxford University Press.

Sen, A. (1979). Equality of what? The Tanner Lecture on Human Values. Stanford: Stanford University.

Sen, A. (2010). The idea of justice. London: Penguin.

Simon, J., Anand, P., et al. (2013). Operationalising the capability approach for outcome measurement in mental health research. Social Science and Medicine. doi:10.1016/j.socscimed.2013.09.019.

Snelling, J. (1994). The effect of chronic pain on the family unit. Journal of Advanced Nursing, 19, 543-551.

Sorensen, E. B., \& Askegaard, S. (2007). Laddering: How (not) to do things with words. Qualitative Market Research: An International Journal, 10(1), 63-77. 
The Australian Medical Services Advisory Committee. Retrieved July 15, 2011, from, http://www.msac. gov.au/.

The Australian Pharmaceutical Benefits Advisory Committee. Retrieved July 15, 2011, from, http://www. health.gov.au/internet/main/publishing.nsf/Content/health-pbs-general-listing-committee3.htm.

The Canadian Agency for Drugs and Technologies in Health. Retrieved July 15, 2011, from, http://www. cadth.ca/index.php/en/home.

The EUROQOL Group. Retrieved 20 January 2012, from, http://www.euroqol.org/home.html.

The Scottish Medicine Consortium. Retrieved July 15, 2011, from, http://www.scottishmedicines.org.uk/.

Thomas, E., Peat, G., et al. (2004). The prevalence of pain and pain interference in a general population of older adults: Cross-sectional findings from the north staffordshire osteoarthritis project (NorStop). Pain, 110, 361-368.

Viswanathan, M., Sudman, S., et al. (2004). Maximum versus meaningful discrimination in scale response: Implications for validity of measurement of consumer perceptions about products. Journal of Business Research, 57, 108-124.

Werner, A., Isaksen, L. W., et al. (2004). 'I am not the kind of woman who complains of everything': Illness stories on self and shame in women with chronic pain. Social Science and Medicine, 59, 1035-1045. 